\title{
Multilinguales
}

\section{Assia Djebar, la rawiya des exhérédées}

Farida Boualit

\section{OpenEdition}

Journals

Édition électronique

URL : http://journals.openedition.org/multilinguales/809

DOI : 10.4000/multilinguales.809

ISSN : 2335-1853

\section{Éditeur}

Université Abderrahmane Mira - Bejaia

\section{Référence électronique}

Farida Boualit, «Assia Djebar, la rawiya des exhérédées », Multilinguales [En ligne], 6 | 2015, mis en ligne le 01 décembre 2015, consulté le 24 septembre 2020. URL : http://journals.openedition.org/ multilinguales/809; DOI : https://doi.org/10.4000/multilinguales.809

Ce document a été généré automatiquement le 24 septembre 2020.

\section{(c) $)(9)$}

Multilinguales est mise à disposition selon les termes de la Licence Creative Commons Attribution -

Pas d'Utilisation Commerciale - Pas de Modification 4.0 International 


\title{
Assia Djebar, la rawiya des exhérédées
}

\author{
Farida Boualit
}

1 Un projet d'écriture traverse l'œuvre d'Assia Djebar, de 1957 à 2007 : donner voix au chapitre aux exhérédées ${ }^{1}$ dont elle fait partie. Dans la présentation a posteriori de son premier drame musical (2001), Les Filles d'Ismaël dans le vent et la tempête (2000), elle commence par décliner son identité historico-culturelle :

Filles d'Ismaël est le titre du drame musical en cinq actes et vingt et un tableaux que j'ai écrit puis dirigé en l'an 2000 pour le Teatro di Roma. Je parle en effet et j'écris d'abord, depuis des décennies, en tant que "fille d'Ismaël". (...) Or, pourquoi ne me sentirais-je, tout autant, sinon davantage, "fille d'Agar", liée à cette épouse répudiée et qui risqua - avec son bébé - de s'asphyxier dans le désert d'Arabie ?²

2 Après la revendication de cette double ascendance, paternelle et maternelle, la « fille d'Ismaël »/ «fille d'Agar» se fait elle-même rawiya, à l'instar d'un de ses personnages, c'est-à-dire, comme elle le précise elle-même, «transmettrice de la mémoire » : « ce drame musical, en remontant aux jours de la mort du Prophète, se veut aussi leçon d'histoire sur quelques mois, à Médine, première capitale de l'Etat de Mohammed $»^{3}$.

3 Le projet de la rawiya est de «transmettre » le passé pour agir sur le cours de l'Histoire. C'est le sens de sa « leçon » : « je tente de réveiller ce passé originel, et d'éclairer, par là même, notre dépossession actuelle, notre humiliation (je ne trouve pas d'autre mot), à nous, femmes vivant à Alger, (...) $»^{4}$.

4 Lire et faire lire le présent des femmes en pays musulmans à la lumière du passé se veut au fondement de toute l'écriture de la "fille d'Ismaël »/ « fille d'Agar », et constitue selon ses mots, « la double face de [s] on "engagement" d'écrivain $»^{5}$.

5 La «dépossession » qu'elle veut "éclairer » est, certes, celle de la femme dans une société misogyne dont, de son propre aveu, elle a eu à souffrir .

6 Mais, «la dépossession » est d'abord celle que l'Histoire a inscrite, comme elle le rappelle dans son discours de réception à l'Académie française, en $2006^{7}$ :

L'Afrique du Nord, du temps de l'Empire français, - comme le reste de l'Afrique de la part de ses coloniaux anglais, portugais ou belges - a subi, un siècle et demi durant, dépossession de ses richesses naturelles, déstructuration de ses assises sociales, et, pour l'Algérie, exclusion dans l'enseignement de ses deux langues identitaires, le berbère séculaire, et la langue arabe dont la qualité poétique ne 
pouvait alors, pour moi, être perçue que dans les versets coraniques qui me restent chers. (...) En ce sens, le monolinguisme français, institué en Algérie coloniale, tendant à dévaluer nos langues maternelles, nous poussa encore davantage à la quête des origines.

7 La citation est volontairement longue pour attester de la place de la dépossession coloniale à l'origine des sujets majeurs que l'auteur traite de son point de vue de «femme-blessure ${ }^{8}$ dans son œuvre polymorphe. En un demi-siècle, Assia Djebar a effectué un parcours sans ruptures, depuis ses débuts décrits ainsi par Jean Dejeux, dans La Littérature féminine de langue française au Maghreb (1994 : 23-24) :

En juin, 1955, une jeune Algérienne, Fatima-Zohra Imalayene passe avec succès le concours d'admission à l'Ecole normale supérieure de Sèvres. C'est la première fois qu'une Algérienne entre à cette célèbre école. Durant l'été 1956, c'est la grève des étudiants en Algérie; par solidarité nationaliste, elle ne passe pas les examens de licence, mais en deux mois, écrit son premier roman, La Soif et le signe Assia Djebar. On est en 1957. Elle a vingt ans.

8 Nous traduisons: «Elle n'avait que vingt ans!». De La Soif, écrit de jeunesse qu'un certain public ne lui pardonne toujours pas, à Nulle part dans la maison de mon père (2007), la " rawiya » a creusé son sillon sans dévier de sa trajectoire : «Tu prenais ta première fiction pour un simple jeu d'hirondelles dans l'espace et soudain, ivre de cet élargissement, tu en échafaudais aussitôt une deuxième, une troisième...Te voici donc à écrire (...) » $(2007: 460)$.

Mais qu'est-ce qu' "écrire » pour une fille d'Ismaël / fille d'Agar? Assia Djebar revient sans cesse sur cette question, au fil des œuvres, comme pour remettre en jeu les termes de la réponse intensifiés par leurs reprises anaphoriques.

Ainsi, dans Vaste est ma prison (1995: 256), «l'écriture est dévoilement, en public, devant les voyeurs qui ricanent... ", comme dans Ces voix qui m'assiègent (1999:64) : « écrire donc pour une femme, si elle ne peut se cantonner dans la diction, lui devient a posteriori dévoilement ».

L'entreprise n'est pas sans risque: «me mettre à nu dans cette langue me fait entretenir un danger permanent de déflagration » (1995: 300), «(...) danger dès lors du dévoiement, oh oui...Ecrire soudain, cela signifiait pour moi, au sens propre, "me dévoyer" » (1999: 64).

Ecrire en "femme d'éducation arabe - ou disons de sensibilité maghrébine - et cela, au creux même de la langue française » (1999: 65), pendant un demi siècle, c'est « sortir du harem » (1999 : 69), se dévoiler/se dévoyer, en imposant une esthétique spécifique.

Pour saisir cette spécificité, il faut retenir que pour Assia Djebar, il existe deux catégories de livres :

d'un côté, ceux à travers les pages desquels est couché, invisible mais tenace, le corps même de l'auteur; d'un autre, tous les livres, petits et grands, inspirés ou simplement habiles et séducteurs, (...) ; ceux de la première catégorie, que nous lisons avec l'obscure sensation que l'auteur(e), couché(e) à jamais depuis lors, tourne pourtant avec nous les pages, relèvent-ils seulement de l'art (...); ne pèsentils pas, de par leur degré de gravité, ou plutôt de leur irréversibilité, plus lourds hélas? (Nulle part dans la maison de mon père, 2007, pp. 469-470).

L'analyse de l'esthétique spécifique d'Assia Djebar, à laquelle est consacré le premier dossier thématique de ce sixième numéro de Multilinguales, répond à cette interrogation, parce qu'il ne fait aucun doute qu'elle est couchée au travers de ses textes et qu'elle en tourne toujours avec nous chaque page. 
11 Dans le premier article, intitulé «Éros, Thanatos et engagement politique de la femme dans Oran, langue morte ", Denise Brahimi montre qu'Assia Djebar, à travers ses personnages féminins, tente en vain de concilier désir amoureux et engagement politique au sens sartrien ; d'où la dimension tragique de ces femmes que Thanatos finit par vaincre.

12 Mais, dans «Le blanc à l'épreuve des rites funéraires dans Le Blanc de l'Algérie d'Assia Djebar ", Mounya Belhocine décrit le combat victorieux des femmes, dont l'auteur, contre Thanatos, dans cette œuvre. Elle explique qu'Assia Djebar décrit les meurtres de ses «amis ", dans le contexte de la terreur intégriste des années 90, en Algérie, en exorcisant la mort pour les ramener à la vie. Ce processus est étudié à travers deux types de stratégies: chromatographique pour l'écriture de la couleur blanche et ethnologique pour la description des rites.

13 Nancy Ali, dans « Assia Djebar et la réécriture de l'histoire au féminin » dans L'Amour, la fantasia, s'intéresse à la manière dont l'auteur s'applique à restituer aux discours historiques sur la colonisation de l'Algérie et la guerre de libération, la part féminine de l'histoire, «ces voix ensevelies ». Pour décrire ce qui est présenté comme une «entreprise spéléologique de la contre-histoire féminine », l'auteur de l'article étudie les relais textuels des métaphores symboles de la libération de la femme (« la plume, la clef, l'objectif de la caméra) et le rôle stratégique des conteuses qui participent à la réécriture de l'Histoire à travers leurs récits.

14 L'article de Dalil Slahdji, "Mémoire en fragments ou l'impossible anamnèse dans L'Amour, la fantasia d'Assia Djebar ", traite du même thème que l'article précédent, mais il est davantage focalisé sur les modalités de combinaison du récit autobiographique et des récits de l'Histoire de l'Algérie; l'autobiographie en tant que récit de soi, étant, chez Assia Djebar, impossible à cause du recours à la langue française qu'elle ne peut faire sienne parce que propriété d'une Histoire collective douloureuse.

Hervé Sanson, auteur " D'une éthique de la traduction: Assia Djebar ou les apories de l'écriture en langue française", se saisit d'une question qui est au centre des préoccupations d'Assia Djebar et qu'il formule ainsi : "comment sauvegarder dans la langue française les scories, les particularités de la langue d'origine?». Il en fera la démonstration à travers notamment la présence de tournures syntaxiques typiques de certains personnages féminins, de « mots porteurs » en arabe et impossibles à traduire en français et qui jouent le rôle d'embrayeurs narratifs, etc. Il conclut que la langue d'Assia Djebar, tenue éloignée de sa culture ancestrale, (sur)investit la langue française de scories en tant que « vecteurs différentiels identitaires ».

Enfin, « Pour une didactisation des nouvelles de Femmes d'Alger dans leur appartement d'Assia Djebar », expose l'opportunité d'enseigner les nouvelles de cet auteur à l'école. Ammouden M’Hand, après avoir exposé l'épineuse question du «document authentique ", traite de la didactisation de ces textes littéraires dans le cadre de l'enseignement du français langue étrangère. L'hypothèse qui sous-tend sa réflexion est que les textes d'auteurs algériens francophones, qui véhiculent des contenus socioculturels familiers aux apprenants débutants, sont à même de faciliter le transfert des connaissances et de contribuer au développement de la compétence plurilingue et pluriculturelle. 


\section{NOTES}

1. «Filles non héritières; exhérédées. (...) Et le déshéritement de la mère produira une nouvelle spoliation, subie et imposée! Voici le seul dialogue possible entre hommes et femmes dans mon pays désormais (...). Par impuissance, j'esquisse à ma manière cette grande misère, source de violence masquée. Ecriture de la dépossession?", dans Assia Djebar, Ces voix qui m’assiègent, Albin Michel, 1999, pp. 260-261.

2. Djebar Assia, «Filles d'Ismaël dans le vent et la tempête », La Pensée de midi 2/2001 ( $\left.\mathrm{N}^{\circ} 5-6\right)$, p. 46-53. URL : https://www.cairn.info/revue-la-pensee-de-midi-2001-2-page-46.htm

3. Idem.

4. Idem.

5. Idem. Sa façon de concevoir l'engagement n'était pas reconnue par certains intellectuels algériens comme Mostefa Lacheraf : «Malek Haddad, Assia Djebar sont des écrivains qui n'ont jamais saisi nos problèmes, même les plus généraux. Ils ont tout ignoré, sinon de leur classe petite bourgeoise, du moins de tout ce qui avait trait à la société algérienne (...) ", cf. "L'avenir de la culture algérienne », in Les temps modernes, $\mathrm{N}^{\circ} 209,1963$, pp. 733-734.

Dans Ces voix qui m'assiègent (Albin Michel, 1999), Assia Djebar raconte : «Autre souvenir : en 1976, un poète à la radio algérienne attaquait encore avec hargne le non-engagement politique (et le succès éditorial) de mon premier roman publié ...en 1957 !» (p .87).

6. A titre d'exemple, Assia Djebar a expliqué la violente polémique qui a marqué le débat qui a suivi la projection de son film La Nouba des femmes du Mont Chenoua, à la cinémathèque algérienne, en 1978: « «Ce que n'a pas supporté le public de la cinémathèque, c'est que j'ai écarté les hommes de mon film. Mais que répondre d'autre que de dire que je n'ai fait que montrer ce qui existe dans la réalité ? ", Bensmaia Réda, «La Nouba des femmes du Mont Chenoua : introduction à l'œuvre fragmentale cinématographique ", dans Sada Niang (Ed.), Littérature et cinéma en Afrique francophone: Ousmane Sembene et Assia Djebar, L'Harmattan, 1996, pp. 161-177.

7. Cf. « Discours de Mme Assia Djebar » à l'Académie française, séance du 22 juin 2006.Disponible sur le site : < http://www.lefigaro.fr/pdf/AssiaDjebar.pdf >

8. "Toute femme s'appelle blessure », tel est le titre de la première partie du roman d'Assia Djebbar Ombre sultane, Albin Michel, 2006, pp. 13-135.

\section{AUTEUR}

\section{FARIDA BOUALIT}

$\mathrm{P} /$ Multilinguales 